\title{
Hyperferritinemia Is a Predictor of Onset of Diabetes in Japanese Males Independently of Decreased Renal Function and Fatty Liver: A Fifteen-Year Follow-Up Study
}

\author{
Yukie Sakuma ${ }^{\mathrm{a}}$, Jun Ogino ${ }^{\mathrm{b}}$, Rie Iwai ${ }^{\mathrm{c}}$, Takashi Inoue ${ }^{\mathrm{a}}$, Haruo Takahashi $^{\mathrm{a}}$, Yoshifumi Suzuki ${ }^{\mathrm{b}}$, \\ Daisuke Kinoshita ${ }^{\mathrm{b}}$, Koji Takemura ${ }^{\mathrm{b}}$, Hidenori Takahashi ${ }^{\mathrm{d}}$, Haruhisa Shimura ${ }^{\mathrm{d}, ~ e}$, \\ Yasunori Sato ${ }^{\mathrm{f}}$, Shouji Yoshida ${ }^{\mathrm{e}}$, Naotake Hashimoto ${ }^{\mathrm{d}, \mathrm{g}}$
}

\begin{abstract}
Background: Type 2 diabetes is an important health concern worldwide. The disease etiology may depend on multiple environmental and genetic factors that cause insulin resistance, including dysregulation of iron storage. The goal of this study was to examine the relationship of the serum ferritin concentration with onset of diabetes over a long period.
\end{abstract}

Methods: Correlations of serum ferritin and metabolic markers with onset of diabetes mellitus were examined over 15 years in 150 males participating in a health screening program.

Results: HOMA- $\beta$ showed a gradual significant decrease in the first 4 years in subjects with ferritin $>190 \mathrm{ng} / \mathrm{mL}$ (group H) compared to those with ferritin $\leq 190 \mathrm{ng} / \mathrm{mL}$, but there was no difference in HOMA-R between these groups. A significant number of cases with onset of diabetes was observed over 15 years (hazard ratio (HR): 3.97), and obesity, fasting blood glucose level, hemoglobin Alc (HbAlc), HOMA-R, fasting immunoreactive insulin (IRI) and C-peptide immunoreactivity (CPR) were all significant in univariate comparison between non-diabetes and diabetes-onset groups. In multivariate analysis, ferritin in group H (HR: 3.25), fatty liver (HR: 3.38), estimated glomerular filtration rate $(\mathrm{eGFR})<70 \mathrm{~mL} / \mathrm{min} / 1.73 \mathrm{~m}^{2}$ (HR: 3.48 ) and high-density lipoprotein (HDL) $<40 \mathrm{mg} / \mathrm{dL}$ (HR: 2.61) were sig-

Manuscript submitted November 12, 2021, accepted November 24, 2021 Published online December 28, 2021

${ }^{a}$ Clinical Research Support Center, Asahi General Hospital, Chiba, Japan ${ }^{b}$ Department of Diabetes and Metabolic Diseases, Asahi General Hospital, Chiba, Japan

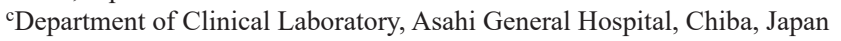

dPreventive Medicine Research Center, Asahi General Hospital, Chiba, Japan eDepartment of Internal Medicine, Asahi General Hospital, Chiba, Japan

fDepartment of Preventive Medicine and Public Health, Keio University School of Medicine, Tokyo, Japan

'Corresponding Author: Naotake Hashimoto, Preventive Medicine Research Center, Asahi General Hospital, I-1326, Asahi, Chiba 289-2511, Japan.

Email: nhashimoto@hospital.asahi.chiba.jp nificant predictive factors for onset of type 2 diabetes mellitus.

Conclusions: These results suggest that the serum ferritin level is an important index for priority intervention in preventive medicine for reduction of onset of diabetes.

Keywords: Type 2 diabetes; Ferritin; Long-term follow-up; Males

\section{Introduction}

Type 2 diabetes (T2D) has become an important health problem worldwide. The disease etiology is multifactorial and not fully understood, but risk factors for T2D are related to lifestyle, such as an overweight status and lack of physical activity. Environmental and genetic factors may lead to insulin resistance and insufficient insulin secretion, which may then lead to onset of $\mathrm{T} 2 \mathrm{D}$, and one candidate factor is body iron storage [1-3]. Thus, the serum ferritin concentration has been proposed as a marker of insulin resistance, and a higher ferritin level was associated with higher HOMA-R in a large non-diabetic population in a US study, suggesting that ferritin may be an independent marker for insulin resistance [4-8]. A positive association between the serum ferritin concentration and increased diabetes prevalence has also been found in several cross-sectional overseas studies [4, 9-12].

In this study, we examined the relationship of the serum ferritin level with onset of diabetes in Japanese subjects. The Japanese population has lower rates of obesity and meat consumption compared with those in Western countries, and lower insulin secretory capacity compared to Caucasians. Correlations of serum ferritin with onset of diabetes and metabolic markers were examined over 15 years in males participating in a health screening program.

\section{Materials and Methods}

A total of 1,567 people visited the Preventive Medicine Re- 


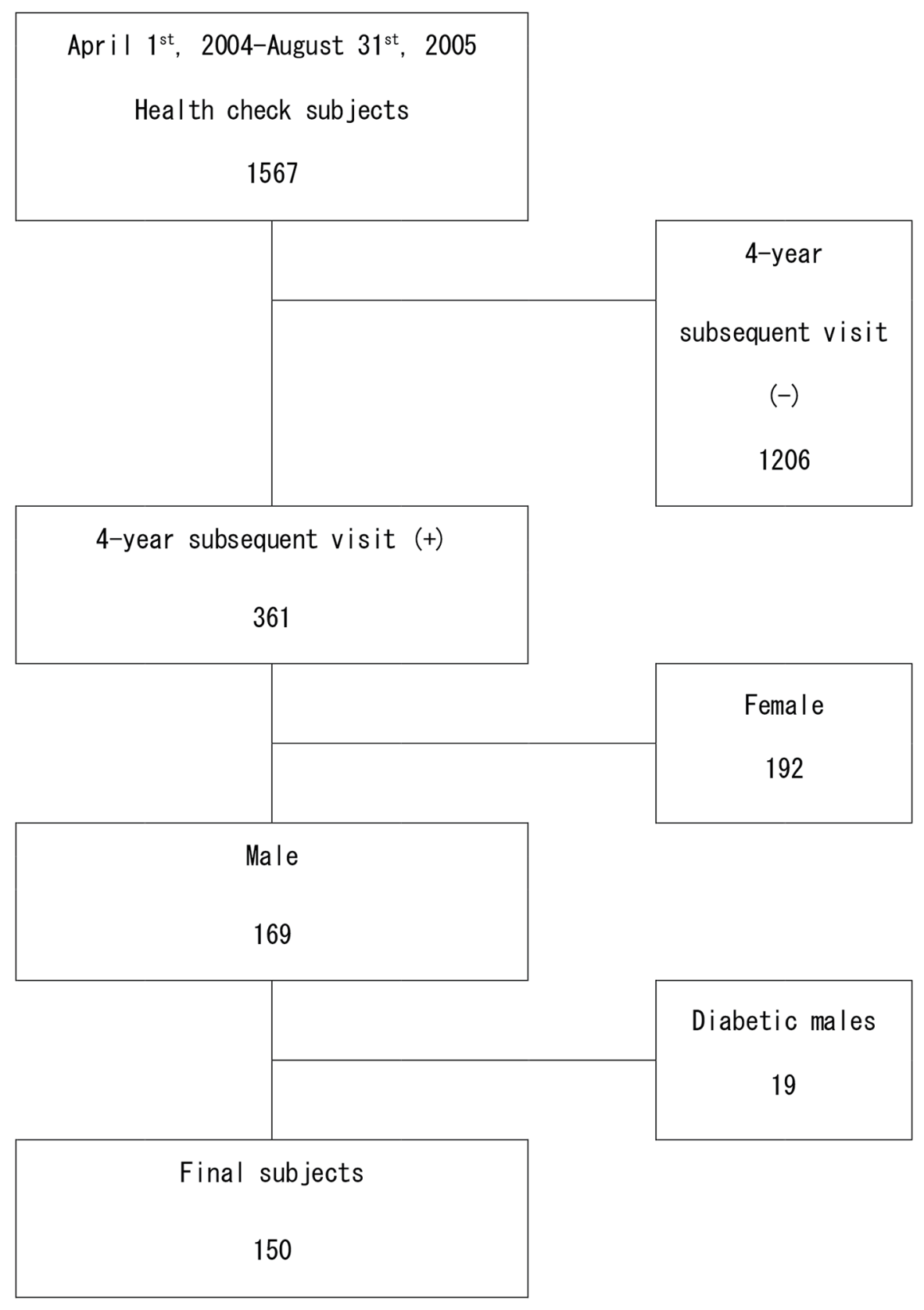

Figure 1. Flow diagram of selection of the subjects at baseline.

search Center at Asahi General Hospital from April 2004 to August 2005. The selection of subjects from these individuals is shown in Figure 1. First, 1,206 people who could not be observed for more than 4 years or did not agree to measurement of serum ferritin were excluded. Then, 192 females were excluded in consideration of changes in serum ferritin levels due to physiology, and 19 males who had already been diagnosed with diabetes were also excluded. The remaining 150 males who did not have diabetes were selected as subjects for the study (Fig. 1). Fatty liver was diagnosed by abdominal ultrasound echography using hepatorenal echo contrast. T2D was diagnosed based on a fasting plasma glucose (FPG) level $\geq 126 \mathrm{mg} / \mathrm{dL}$ and hemoglobin A1c (HbA1c) $\geq 6.5 \%$ (National Glycohemoglobin Standardization Program (NGSP)), a postprandial plasma glucose (PPG) level $\geq 200 \mathrm{mg} / \mathrm{dL}$, self-reported diagnosis by a physician and/or taking insulin or any oral antidiabetic medications. Hypertension was diagnosed based on systolic blood pressure $(\mathrm{SBP}) \geq 140 \mathrm{~mm} \mathrm{Hg}$ or diastolic blood pressure (DBP) $\geq 90 \mathrm{~mm}$ $\mathrm{Hg}$; obesity was defined as a body mass index (BMI) $\geq 25 \mathrm{~kg}$ / $\mathrm{m}^{2}$ according to Japanese standard categories; and dyslipidemia was diagnosed based on LDL cholesterol (LDL-C) $\geq 140 \mathrm{mg} /$ $\mathrm{dL}$, HDL cholesterol $<40 \mathrm{mg} / \mathrm{dL}$, or fasting triglyceride $(\mathrm{TG}) \geq$ $150 \mathrm{mg} / \mathrm{dL}$. Current and past smokers were defined as smokers and those who had never smoked were defined as non-smokers. 
Table 1. Baseline Characteristics of Subjects With and Without New-Onset T2D in 15 Years

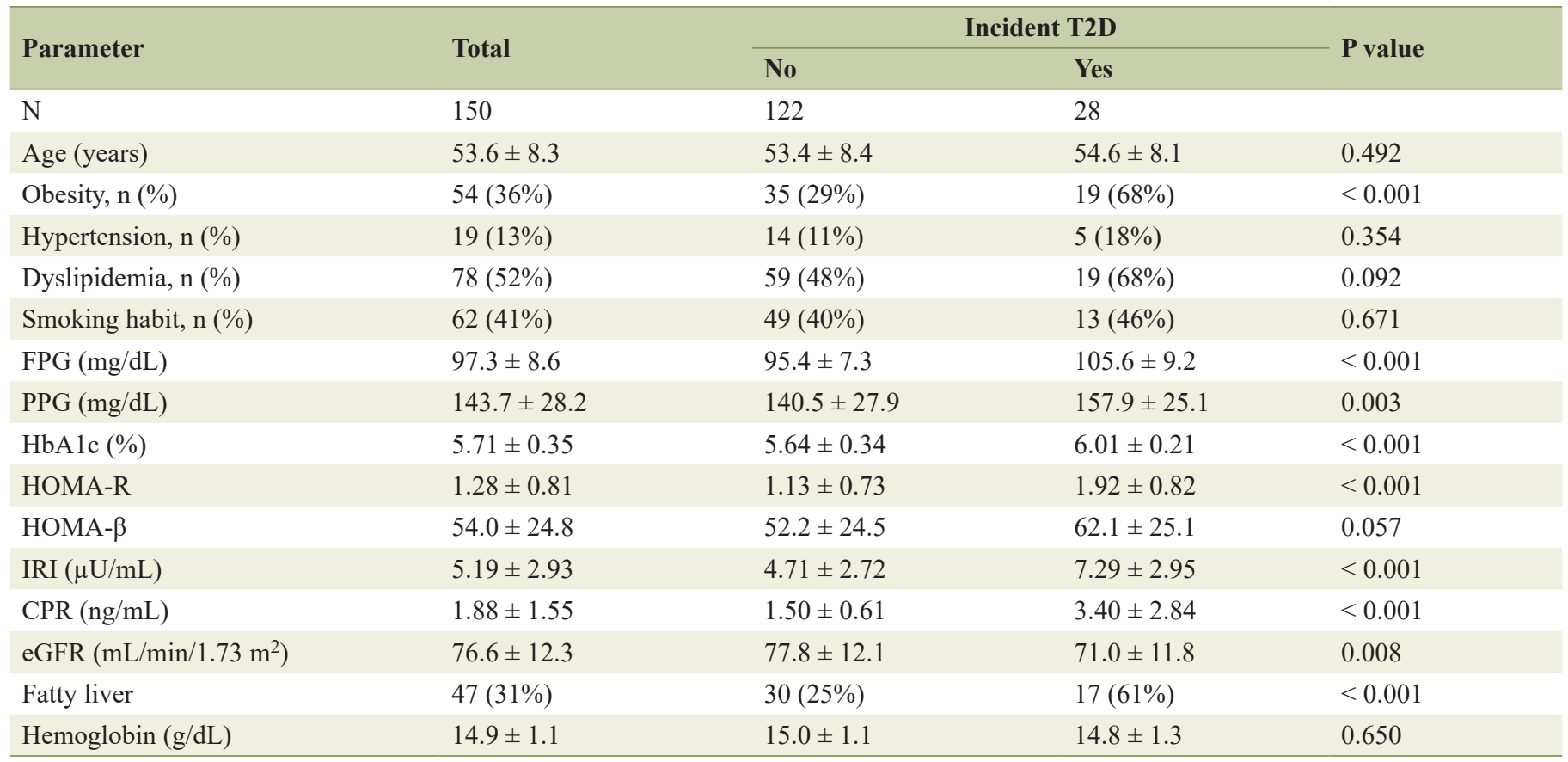

Values are means \pm SD. T2D: type 2 diabetes; SD: standard deviation; FPG: fasting plasma glucose; PPG: postprandial glucose; HbA1C: hemoglobin A1c; IRI: immunoreactive insulin; CPR: C-peptide immunoreactivity; eGFR: estimated glomerular filtration rate. HOMA-R = FPG $\times$ IRI/405; HOMA- $\beta$ $=\mid R I \times 360 /(F P G-63)$.

\section{Statistical analysis}

A receiver operating characteristic (ROC) curve was drawn for ferritin levels with onset of diabetes as an event, and the ferritin level giving the best sensitivity and specificity was calculated. Subjects were divided into those in which ferritin was high (> $190 \mathrm{ng} / \mathrm{mL}$, group $\mathrm{H})$ and low $(\leq 190 \mathrm{ng} / \mathrm{mL}$, group L). Univariate analysis was performed using the Kaplan-Meier method and a competing risks model. To identify predictors of diabetes onset and risk factors for developing diabetes, factors found to be significant in univariate analysis were included in multivariate analysis using a Fine-Gray model. Statistical significance was defined as a $\mathrm{P}$ value $<0.05$ in all analyses.

\section{Ethical review}

The ethics committee of Asahi General Hospital approved the study on January 20, 2021 (approval no. 2021011913). All procedures followed were in accordance with the ethical standards of the responsible committee on human experimentation (institutional and national) and with the Helsinki Declaration of 1964 and later versions. Informed consent or asubstitute for this consent was obtained from all subjects for inclusion in the study.

\section{Results}

The 150 male subjects in the study were attendees at the Pre- ventive Medicine Research Center for 15 years (Fig. 1). Onset of diabetes and factors related to onset were followed in these subjects. The baseline clinical characteristics are shown in Table 1. Obesity, FPG, PPG, HbA1c, HOMA-R, immunoreactive insulin (IRI) and C-peptide immunoreactivity (CPR) at baseline were higher in subjects with onset of diabetes after 15 years follow-up. The area of under the curve (AUC) of ROC curve about the association of ferritin $>190 \mathrm{ng} / \mathrm{mL}$ with onset of diabetes was 0.55 (95\% confidence interval (CI): 0.42 - 0.69). The AUC of ferritin was not very high at 0.55 , but it was higher than $\mathrm{Hb}$ (AUC: 0.504; 95\% CI: $0.385-0.623$ ), and we think iron deficiency did not explain the onset of diabetes, but rather oxidative stress. HOMA- $\beta$ in group $\mathrm{H}$ decreased gradually in the first 4 years of the study (Fig. 2) and differed significantly between groups $\mathrm{H}$ and $\mathrm{L}$ after 4 years $(\mathrm{P}<0.01)$. In contrast, there was no significant difference in HOMA-R between the two groups.

Onset of diabetes increased gradually in group $\mathrm{H}$ and reached a significantly higher level compared with group L over 15 years (Fig. 3, hazard ratio (HR): 3.97, 95\% CI: 1.87 8.41, $\mathrm{P}<0.001)$ using Fine-Gray analysis. At 15 years, obesity, SBP, DBP, TG, HDL-C, estimated glomerular filtration rate (eGFR), fatty liver and C-reactive protein (CRP) showed significant univariate differences between the non-diabetes and diabetes onset groups (Table 2). In multivariate analysis using these factors in the Fine-Gray model, ferritin in group H (HR: 2.77), fatty liver (HR: 3.06), eGFR $<70 \mathrm{~mL} / \mathrm{min} / 1.73 \mathrm{~m}^{2}$ (HR: 2.75) and HDL $<40 \mathrm{mg} / \mathrm{dL}$ (HR: 2.40) were significant predictive factors for onset of T2D (Table 2). 

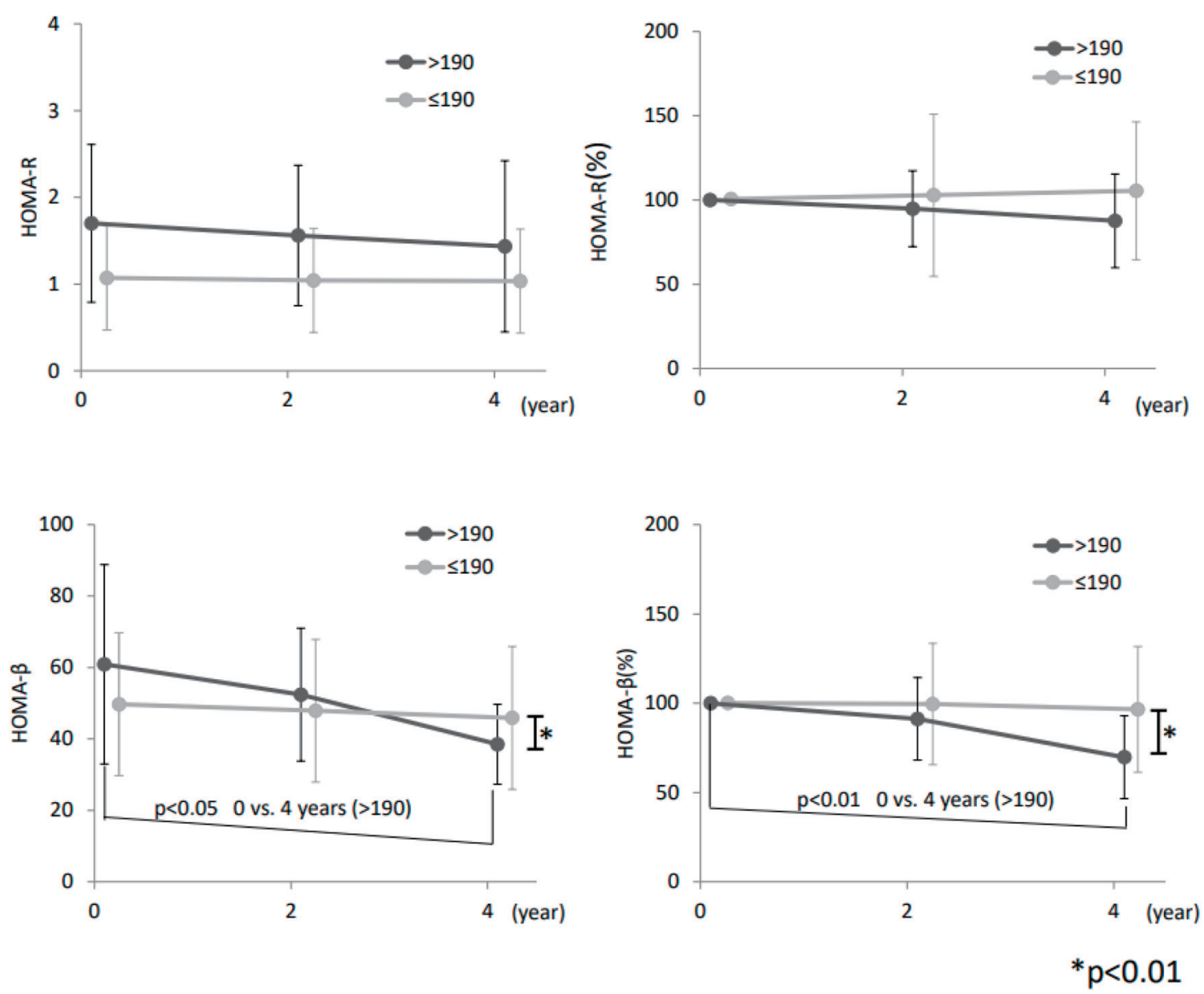

Figure 2. Changes in HOMA-R and HOMA- $\beta$. HOMA- $\beta$ decreased from the baseline level in group $\mathrm{H}$, but HOMA-R did not differ between the two groups. Error bars show standard deviation of means. Statistical significance is performed by paired Student's $t$-test.

\section{Discussion}

Serum ferritin is a marker of iron metabolism and a wellknown marker of oxidative stress and inflammation [13]. Serum iron levels are associated with hereditary diseases such as hemochromatosis and aceruloplasminemia [14-16], and in hemochromatosis, the prevalence of diabetes is reported to be $23 \%$ and that of impaired glucose tolerance (IGT) is $30 \%$, with patients with both hemochromatosis and IGT having a $68 \%$ decrease in acute insulin response to glucose compared with those with normal glucose tolerance [16]. These findings suggest that decreased insulin secretion occurs in the early stage of impaired glucose metabolism in subjects with hyperferritinemia. In the current study, HOMA- $\beta$ decreased with insulin secretion capacity from baseline to 4 years in subjects with high serum ferritin compared to those with normal ferritin, suggesting that a gradual decrease of insulin secretion over 15 years was the final cause of onset of T2D on the primary basis of insulin resistance.

In hemochromatosis, iron excess results in $\beta$-cell oxidant stress and decreased insulin secretory capacity due to $\beta$-cell apoptosis and desensitization of glucose-induced insulin secretion [17]. Dietary iron restriction or iron chelation is protective against diabetes and loss of $\beta$-cell function in obese mice [18], and recent studies of iron metabolism in hemochromatosis have focused on the roles of hepcidin, ferroportin and HFE [14, 19-21]. Patients with hemochromatosis and diabetes have a severely reduction in immunoreactive $\beta$ cells in the pancreas [22], and serum and muscle ferritin levels may be correlated with muscle inflammation and insulin resistance in obese people [2, 23, 24]. Hyperinsulinemia caused by hepatic insulin resistance due to hyperferritinemia may stimulate cellular iron uptake, leading to a vicious circle in glucose homeostasis [25]. Clinically, hyperferritinemia may finally lead to development of arteriosclerosis via M1 macrophages in arterial vessels [26], with serious consequences in terms of cardiovascular diseases.

Studies in Europe and the USA have shown that a high serum ferritin level is a component of metabolic syndrome and a possible cause of T2D [23, 27]. In our study, onset of diabetes gradually increased in the high ferritin group over 5,10 and 15 years, and onset of other events may slowly progress in parallel with this course. However, the ferritin level considered to 


\section{Cumulative incidence (\%)}

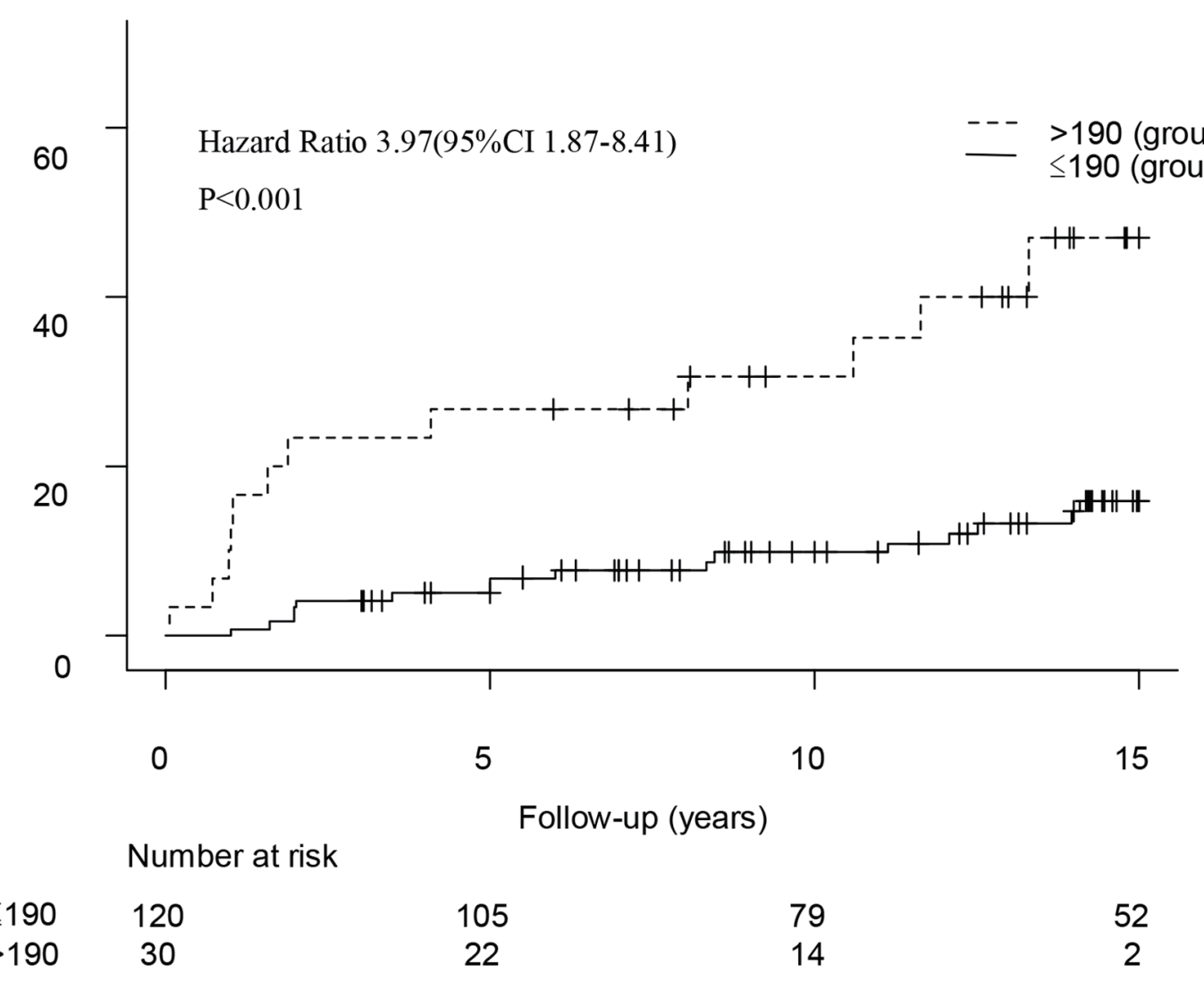

Figure 3. Kaplan-Meier analysis showed a significant increase in the rate of T2D onset in the group with serum ferritin levels > $190 \mathrm{ng} / \mathrm{mL}$ (group H). Significant onset of diabetes in group H was observed at 5, 10 and 15 years, with odds ratios of 6.9 (2.2 21.9) $(P<0.01), 4.2(1.6-11.5)(P<0.01)$ and $4.3(1.8-10.7)(P<0.01)$, respectively. T2D: type 2 diabetes.

be a risk for developing diabetes was lower in the current study compared to that in other countries [9, 28, 29]. In Japan, obesity is less common and diabetes may develop due to environmental factors that decrease insulin secretory capacity, even in the absence of obesity [30-33]. In our study, the incidence of diabetes was tripled in males with ferritin $\geq 190 \mathrm{ng} / \mathrm{mL}$ after 15 years. Ferritin levels of 228 - $939 \mathrm{ng} / \mathrm{mL}$ have been proposed to cause about a 1.5 times increase in development of diabetes in 16.8 years in other countries. This suggests that Japanese patients with high ferritin may be highly susceptible to onset of diabetes, even if these levels are not as high as those found in Europe and the USA $[1,10]$.

In addition to the serum ferritin level, a decrease in HDL$\mathrm{C}$, a decrease in eGFR, and the presence of fatty liver were identified in multivariate analysis as factors influencing onset of diabetes in the current study. Fatty liver including circulating glycerolipids has recently been associated with an increased incidence of T2D in the Chinese population in a 6-year resurvey [34]. Fatty liver is now referred to as metabolic-associated fatty liver disease (MAFLD), as a condition with cytokine abnormalities and inflammation, changes in intestinal bacteria, abnormal amino acid metabolism due to glucagon and insulin resistance, and ultimately a high rate of diabetes $[15,35]$. Non-alcoholic steatohepatitis (NASH) is believed to progress to liver cirrhosis and liver cancer, and may lead to diabetes and to systemic arteriosclerosis and development of cancer, which may become more problematic with increasing obesity. However, our data indicated that the fibrosis-4 (FIB-4) index was not a significant predictor for onset of diabetes after 15 years, and liver fibrosis was not found to be related to onset of diabetes. It is unclear whether these findings are temporal or dependent on race. A decrease of eGFR was an independent risk factor for diabetes onset after 15 years follow-up in our study, and eGFR $\leq 70 \mathrm{~mL} / \mathrm{min} / 1.73 \mathrm{~m}^{2}$ has also previously been shown to be significant in development of diabetes [36], although the mechanism is unclear.

A recent report showed an increased onset of diabetes after 5 years in non-obese people with a high serum ferritin level in Japan [37]. This is of particular interest in the context of Japanese patients, and is consistent with our observations over a much longer span of 15 years. We also examined insulin secretion for the first 4 years, and we concluded that the main 
Table 2. Hazard Ratios for Incidence of Type 2 Diabetes in Univariate and Multivariate Analyses Using a Fine-Gray Model

\begin{tabular}{lllll}
\hline Variables & Univariate, HR (95\% CI) & P value & Multivariate, aHR (95\% CI) & P value \\
\hline $\mathrm{BMI} \geq 25 \mathrm{~kg} / \mathrm{m}^{2}$ & $4.28(1.92-9.52)$ & $<0.001$ & $1.14(0.41-3.13)$ & 0.800 \\
$\mathrm{SBP} \geq 130 \mathrm{~mm} \mathrm{Hg}$ & $2.58(1.23-5.43)$ & 0.012 & $1.61(0.64-4.09)$ & 0.320 \\
$\mathrm{DBP} \geq 85 \mathrm{~mm} \mathrm{Hg}$ & $2.89(1.32-6.30)$ & 0.008 & $1.37(0.60-3.09)$ & 0.450 \\
$\mathrm{TG} \geq 150 \mathrm{mg} / \mathrm{dL}$ & $2.42(1.15-5.08)$ & 0.020 & $1.15(0.45-2.95)$ & 0.770 \\
$\mathrm{HDL}<40 \mathrm{mg} / \mathrm{dL}$ & $2.48(1.08-5.67)$ & 0.031 & $2.40(1.03-5.57)$ \\
$\mathrm{LDL} \geq 140 \mathrm{mg} / \mathrm{dL}$ & $1.35(0.60-3.01)$ & 0.470 & & 0.042 \\
$\mathrm{eGFR}<70 \mathrm{~mL} / \mathrm{min} / 1.73 \mathrm{~m}^{2}$ & $4.30(2.03-9.14)$ & $<0.001$ & $2.75(1.05-7.20)$ \\
Fatty $\operatorname{liver}$ & $4.38(2.06-9.30)$ & $<0.001$ & $3.06(1.23-7.61)$ \\
Uric acid $\geq 7.0 \mathrm{mg} / \mathrm{dL}$ & $1.56(0.71-3.41)$ & 0.270 & & 0.040 \\
$\mathrm{CRP} \geq 0.1 \mathrm{mg} / \mathrm{dL}$ & $2.36(1.13-4.91)$ & 0.022 & $1.07(0.44-2.58)$ \\
ALT $\geq 50 \mathrm{U} / \mathrm{L}$ & $1.78(0.66-4.76)$ & 0.250 & & 0.016 \\
Ferritin $>190 \mathrm{ng} / \mathrm{mL}$ & $3.97(1.87-8.41)$ & $<0.001$ & $2.77(1.13-6.80)$ \\
\hline
\end{tabular}

HR: hazard ratio; Cl: confidence interval; aHR: adjusted hazard ratio; BMI: body mass index; SBP: systolic blood pressure; DBP: diastolic blood pressure; TG: triglycerides; HDL: high-density lipoprotein; LDL: low-density lipoprotein; eGFR: estimated glomerular filtration rate; CRP: C-reactive protein; ALT: alanine transaminase.

cause of the increased incidence of diabetes may be a decrease in insulin secretion.

The limitations of the study include its performance at the Preventive Medicine Research Center, which prevented assessment of the status of use of drugs other than those for diabetes. It was also not possible to examine exercise and diet in daily life, to determine the insulin secretory capacity each year, or to record the family history of diabetes. In addition, we focused on people who visited the center frequently for follow-up over several years, especially those who continued to visit for the first 4 years to check insulin secretion and resistance indicators, and those who understood the purpose of ferritin measurement. This decreased the number of cases, but the initial case selection was performed randomly.

The increasing number of patients with diabetes in Japan requires early identification of risk factors and performance of priority intervention to decrease the rate of onset of diabetes. Given the fewer people with obesity in Japan compared to Europe and the USA, the serum ferritin level provides a simple measurement using a single blood sample that can be used as an index for the risk of developing fatty liver, rather than requiring evidence for the presence of fatty liver. Thus, the serum ferritin level may be an important index of the need for priority intervention as preventive medicine for reduction of onset of diabetes.

\section{Acknowledgments}

None to declare.

\section{Financial Disclosure}

None to declare.

\section{Conflict of Interest}

None to declare.

\section{Informed Consent}

Informed consent was obtained.

\section{Author Contributions}

YS, NH, and JO examined the subjects and wrote the manuscript. RI, TI, HT, YS, DK, KT, HT, HS, and SY reviewed manuscript. YS helped the analytical assistance.

\section{Data Availability}

The authors declare that data supporting the findings of this report are available within the article.

\section{References}

1. Kunutsor SK, Apekey TA, Walley J, Kain K. Ferritin levels and risk of type 2 diabetes mellitus: an updated systematic review and meta-analysis of prospective evidence. Diabetes Metab Res Rev. 2013;29(4):308-318.

2. Fernandez-Real JM, Manco M. Effects of iron overload on chronic metabolic diseases. Lancet Diabetes Endocrinol. 2014;2(6):513-526.

3. Orban E, Schwab S, Thorand B, Huth C. Association of iron indices and type 2 diabetes: a meta-analysis of observational studies. Diabetes Metab Res Rev. 
2014;30(5):372-394.

4. Chen J, Wildman RP, Hamm LL, Muntner P, Reynolds $\mathrm{K}$, Whelton PK, He J, et al. Association between inflammation and insulin resistance in U.S. nondiabetic adults: results from the Third National Health and Nutrition Examination Survey. Diabetes Care. 2004;27(12):29602965.

5. Abril-Ulloa V, Flores-Mateo G, Sola-Alberich R, Manuely-Keenoy B, Arija V. Ferritin levels and risk of metabolic syndrome: meta-analysis of observational studies. BMC Public Health. 2014;14:483.

6. Sachinidis A, Doumas M, Imprialos K, Stavropoulos K, Katsimardou A, Athyros VG. Dysmetabolic iron overload in metabolic syndrome. Curr Pharm Des. 2020;26(10):1019-1024.

7. Gao S, Zhao D, Qi Y, Wang M, Zhao F, Sun J, Liu J. The association between serum ferritin levels and the risk of new-onset type 2 diabetes mellitus: A 10-year follow-up of the Chinese Multi-Provincial Cohort Study. Diabetes Res Clin Pract. 2017;130:154-162.

8. Forouhi NG, Harding AH, Allison M, Sandhu MS, Welch A, Luben R, Bingham S, et al. Elevated serum ferritin levels predict new-onset type 2 diabetes: results from the EPIC-Norfolk prospective study. Diabetologia. 2007;50(5):949-956.

9. Diaz-Lopez A, Iglesias-Vazquez L, Palleja-Millan M, Rey Renones C, Flores Mateo G, Arija V. Association between iron status and incident type 2 diabetes: a population-based cohort study. Nutrients. 2020;12(11):32493264.

10. Aregbesola A, Voutilainen S, Virtanen JK, Mursu J, Tuomainen TP. Body iron stores and the risk of type 2 diabetes in middle-aged men. Eur J Endocrinol. 2013;169(2):247253.

11. Jiang L, Wang K, Lo K, Zhong Y, Yang A, Fang X, Akezhuoli H, et al. Sex-specific association of circulating ferritin level and risk of type 2 diabetes: a dose-response meta-analysis of prospective studies. J Clin Endocrinol Metab. 2019;104(10):4539-4551.

12. Sun L, Zong G, Pan A, Ye X, Li H, Yu Z, Zhao Y, et al. Elevated plasma ferritin is associated with increased incidence of type 2 diabetes in middle-aged and elderly Chinese adults. J Nutr. 2013;143(9):1459-1465.

13. Yauger YJ, Bermudez S, Moritz KE, Glaser E, Stoica $\mathrm{B}$, Byrnes KR. Iron accentuated reactive oxygen species release by NADPH oxidase in activated microglia contributes to oxidative stress in vitro. J Neuroinflammation. 2019;16(1):41.

14. Barton JC, Acton RT. Diabetes in HFE hemochromatosis. J Diabetes Res. 2017;2017:9826930.

15. Niederau C, Berger M, Stremmel W, Starke A, Strohmeyer G, Ebert R, Siegel E, et al. Hyperinsulinaemia in non-cirrhotic haemochromatosis: impaired hepatic insulin degradation? Diabetologia. 1984;26(6):441-444.

16. McClain DA, Abraham D, Rogers J, Brady R, Gault P, Ajioka R, Kushner JP. High prevalence of abnormal glucose homeostasis secondary to decreased insulin secretion in individuals with hereditary haemochromatosis. Diabetologia. 2006;49(7):1661-1669.
17. Cooksey RC, Jouihan HA, Ajioka RS, Hazel MW, Jones DL, Kushner JP, McClain DA. Oxidative stress, betacell apoptosis, and decreased insulin secretory capacity in mouse models of hemochromatosis. Endocrinology. 2004;145(11):5305-5312.

18. Cooksey RC, Jones D, Gabrielsen S, Huang J, Simcox JA, Luo B, Soesanto Y, et al. Dietary iron restriction or iron chelation protects from diabetes and loss of beta-cell function in the obese (ob/ob lep-/-) mouse. Am J Physiol Endocrinol Metab. 2010;298(6):E1236-1243.

19. Piperno A, Pelucchi S, Mariani R. Inherited iron overload disorders. Transl Gastroenterol Hepatol. 2020;5:25.

20. Wunderer F, Traeger L, Sigurslid HH, Meybohm P, Bloch DB, Malhotra R. The role of hepcidin and iron homeostasis in atherosclerosis. Pharmacol Res. 2020;153:104664.

21. Pan Y, Ren Z, Gao S, Shen J, Wang L, Xu Z, Yu Y, et al. Structural basis of ion transport and inhibition in ferroportin. Nat Commun. 2020;11(1):5686.

22. Rahier J, Loozen S, Goebbels RM, Abrahem M. The haemochromatotic human pancreas: a quantitative immunohistochemical and ultrastructural study. Diabetologia. 1987;30(1):5-12.

23. Torrance JD, Charlton RW, Schmaman A, Lynch SR, Bothwell TH. Storage iron in "muscle". J Clin Pathol. 1968;21(4):495-500.

24. Ryan BJ, Foug KL, Gioscia-Ryan RA, Ludzki AC, Ahn C, Schleh MW, Gillen JB, et al. Skeletal muscle ferritin abundance is tightly related to plasma ferritin concentration in adults with obesity. Exp Physiol. 2020;105(11):18081814.

25. Davis RJ, Corvera S, Czech MP. Insulin stimulates cellular iron uptake and causes the redistribution of intracellular transferrin receptors to the plasma membrane. J Biol Chem. 1986;261(19):8708-8711.

26. Vinchi F, Porto G, Simmelbauer A, Altamura S, Passos ST, Garbowski M, Silva AMN, et al. Atherosclerosis is aggravated by iron overload and ameliorated by dietary and pharmacological iron restriction. Eur Heart J. 2020;41(28):2681-2695.

27. Ford ES, Cogswell ME. Diabetes and serum ferritin concentration among U.S. adults. Diabetes Care. 1999;22(12):1978-1983.

28. Chen L, Li Y, Zhang F, Zhang S, Zhou X, Ji L. Elevated serum ferritin concentration is associated with incident type 2 diabetes mellitus in a Chinese population: A prospective cohort study. Diabetes Res Clin Pract. 2018;139:155-162.

29. Kim CH, Kim HK, Bae SJ, Park JY, Lee KU. Association of elevated serum ferritin concentration with insulin resistance and impaired glucose metabolism in Korean men and women. Metabolism. 2011;60(3):414-420.

30. Chen KW, Boyko EJ, Bergstrom RW, Leonetti DL, Newell-Morris L, Wahl PW, Fujimoto WY. Earlier appearance of impaired insulin secretion than of visceral adiposity in the pathogenesis of NIDDM. 5-Year follow-up of initially nondiabetic Japanese-American men. Diabetes Care. 1995;18(6):747-753.

31. Kodama K, Tojjar D, Yamada S, Toda K, Patel CJ, Butte AJ. Ethnic differences in the relationship between insulin sensitivity and insulin response: a systematic review and 
meta-analysis. Diabetes Care. 2013;36(6):1789-1796.

32. Fujimoto WY. Overview of non-insulin-dependent diabetes mellitus (NIDDM) in different population groups. Diabet Med. 1996;13(9 Suppl 6):S7-10.

33. Fukushima M, Usami M, Ikeda M, Nakai Y, Taniguchi A, Matsuura T, Suzuki H, et al. Insulin secretion and insulin sensitivity at different stages of glucose tolerance: a cross-sectional study of Japanese type 2 diabetes. Metabolism. 2004;53(7):831-835.

34. Niu Z, Wu Q, Sun L, Qi Q, Zheng H, Li H, Zeng R, et al. Circulating glycerolipids, fatty liver index, and incidence of type 2 diabetes: a prospective study among Chinese. J Clin Endocrinol Metab. 2021;106(7):2010-2020.
35. Tobari M, Hashimoto E, Taniai M, Ikarashi Y, Kodama $\mathrm{K}$, Kogiso T, Tokushige K, et al. Characteristics of nonalcoholic steatohepatitis among lean patients in Japan: Not uncommon and not always benign. J Gastroenterol Hepatol. 2019;34(8):1404-1410.

36. Wang IK, Tsai TH, Hung YC, Wang TY, Yen TH, Lin CL, Sung FC. Increased risk of new-onset type 2 diabetes in people with chronic kidney disease. Int Urol Nephrol. 2019;51(4):707-712.

37. Akter S, Nanri A, Kuwahara K, Matsushita Y, Nakagawa T, Konishi M, Honda T, et al. Circulating ferritin concentrations and risk of type 2 diabetes in Japanese individuals. J Diabetes Investig. 2017;8(4):462-470. 